\title{
Precocious, selective and successful feeding of larval billfishes in the oceanic Straits of Florida
}

\author{
Joel K. Llopiz*, Robert K. Cowen \\ Rosenstiel School of Marine and Atmospheric Science, Division of Marine Biology and Fisheries, University of Miami, \\ 4600 Rickenbacker Causeway, Miami, Florida 33149, USA
}

\begin{abstract}
The oligotrophic open ocean of low latitudes is larval fish habitat for a diversity of resident and migratory species. It is hypothesized that these waters, relative to coastal regions, yield reduced predation mortality, but little is known regarding the feeding and feeding environment of these larvae and the extent to which a nutritional tradeoff may exist, whereby lower predation mortality is accompanied by poor feeding conditions. Monthly sampling of larval billfishes (Istiophoridae) across the Straits of Florida over 2 yr allowed for an investigation of the temporal, spatial and ontogenetic variability in the feeding of sailfish Istiophorus platypterus and blue marlin Makaira nigricans. Consumed prey were numerically dominated (90\%) by 2 crustaceans: a copepod (Farranula; mainly F. gracilis) and a cladoceran (Evadne; mainly E. tergestina), with relative proportions displaying marked spatial variability. These prey were consumed throughout early larval ontogeny, from first feeding through piscivorous lengths (>5 mm), until piscivory became exclusive near $12 \mathrm{~mm}$. High daytime feeding incidence (0.94) and rapid digestion ( $3.5 \mathrm{~h})$ support generally frequent and successful feeding by billfish larvae. Prey selectivity was illustrated by preference for Evadne over Farranula and a near absence of calanoid copepods from diets despite high environmental concentrations. Gut fullness exhibited a distinct sunset peak and also differed significantly with larval length and year, but not with season or location. A gut evacuation rate was used to estimate a daily ration of 29 to $75 \%$ of gut-free body weight, varying greatly with model selection but also with daylight length. Although potentially unique to the Straits of Florida and larval billfishes, these results contradict the general presumption that the subtropical open ocean is nutritionally constraining for larval fish.
\end{abstract}

KEY WORDS: Fish larvae $\cdot$ Larval fish feeding $\cdot$ Istiophoridae $\cdot$ Piscivory $\cdot$ Ontogenetic shift $\cdot$ Daily ration $\cdot$ Istiophorus platypterus $\cdot$ Makaira nigricans

\section{Resale or republication not permitted without written consent of the publisher}

\section{INTRODUCTION}

The inherent influence of feeding on the survival of larval fishes is the basis for nearly a century's worth of research addressing questions of recruitment variability and stock resilience. Yet, while high-latitude studies on the early life history of fishes often focus on mortality and trophic aspects, there has been a trend in low latitudes to emphasize the role of transport and settlement processes with little attention to the dynamics of feeding. Transport to suitable settlement habitat is crucial for reef fishes (Cowen et al. 2006), but the larvae of oceanic pelagic species such as istiophorid billfishes do not need to reach settlement habitat. Therefore, the survival of these larvae to later stages should depend more heavily upon the nutrition-mediated processes of starvation, growth and predation. Additionally, billfishes and many other taxa specifically place their progeny in the low-latitude open ocean, often undertaking extensive migrations to do so (Bakun 1996); however, the potential nutritional costs of this strategy to the larvae are poorly understood.

The low-latitude oceanic environment differs notably from higher latitudes in that it lacks the distinct primary and secondary productivity peaks that may drive similar peaks in fish spawning (e.g. Cushing 1990). Instead, many tropical and subtropical fishes have adopted a strategy of spawning multiple times over a protracted spawning season of many months or even throughout the year (Robertson 1991), possibly to 
ensure the survival of some offspring in an unpredictable and constraining environment. Consequently, investigating larval fish feeding dynamics in lower latitudes at temporal and spatial scales commensurate with those of spawning is essential to understanding the potential role of feeding in survival to later stages.

Previous work on the feeding of larval istiophorid billfishes in the Indian and Pacific Oceans (Gorbunova \& Lipskaya 1975, Uotani \& Ueyanagi 1997) suffers from either low sample sizes or limited analyses, especially regarding variability with space and time. In the Atlantic Ocean, there is an even greater paucity of data, with only a handful of small studies reporting on a combined total of 45 larvae (Voss 1953, Gehringer 1956, Schekter 1971). The feeding habits of the youngest individuals, including the first-feeding stage, and any variability with time, space and prey availability, are yet to be described. However, it is clear from previous work that larval istiophorids are piscivorous, with individuals as small as $6 \mathrm{~mm}$ standard length consuming other fish larvae, presumably to meet the demands of their characteristically fast growth (Sponaugle et al. 2005).

As part of a large-scale study investigating the early life stages and spawning of billfishes, this work reports on the trophic role of larval istiophorid billfishes in the plankton of the Straits of Florida. Novel sampling techniques and the hydrography of the region allowed for monthly collections throughout 2003 and 2004, and thus the ability to investigate the spatial, temporal and ontogenetic variability in larval sailfish Istiophorus platypterus and blue marlin Makaira nigricans trophodynamics. We couple the results on diet with prey selectivity analyses and estimates of evacuation rate and daily ration, as well as documentation of the ontogenetic changes of the gastrointestinal tract.

\section{MATERIALS AND METHODS}

Area of study and field collection. Plankton sampling occurred within the Straits of Florida (SOF; Fig. 1) from the Florida shelf break south of Miami to the Great Bahama Bank south of Bimini, Bahamas $\left(25.5^{\circ} \mathrm{N}\right.$ parallel). This narrow yet oceanic region, containing the Florida Current and its characteristically strong northerly flow, was sampled monthly along a transect of 17 stations (numbered west to east) during 2003 and 2004. The 3 western- and eastern-most stations were $\sim 2 \mathrm{~km}$ apart with the remaining central stations $\sim 5.5 \mathrm{~km}$ apart. Cruises took place near the beginning of each month and larval billfishes included in these analyses were collected from April to November 2003 and June to October 2004. For subsurface plankton sampling, we utilized a novel design (Guigand et al. 2005) of the multiple opening closing net and

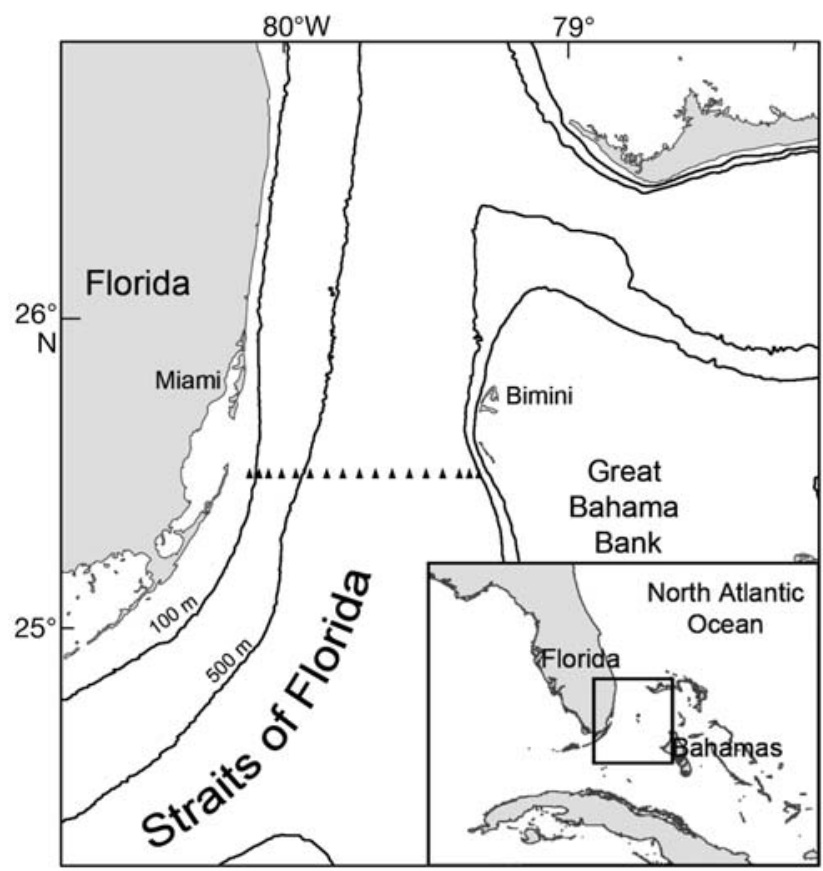

Fig. 1. Western North Atlantic (inset) and the Straits of Florida region where a transect of 17 stations $(\mathbf{\Lambda}$, numbered west to east) from the Florida shelf break just south of Miami to the Great Bahama Bank south of Bimini, Bahamas, was sampled monthly in 2003 and 2004

environmental sensing system (MOCNESS) whereby 2 systems of different opening and mesh sizes were adjoined ( $4 \mathrm{~m}^{2}, 1 \mathrm{~mm}$ mesh and $1 \mathrm{~m}^{2}, 150 \mu \mathrm{m}$ mesh). The MOCNESS obliquely sampled depth intervals of $25 \mathrm{~m}\left(\sim 5 \mathrm{~min}\right.$ interval ${ }^{-1}$ at a speed of $\left.\sim 1.5 \mathrm{~m} \mathrm{~s}^{-1}\right)$ from $100 \mathrm{~m}$ up to $1 \mathrm{~m}$ at all but the shallower westernmost station (where sampling was from $50 \mathrm{~m}$ depth). Adjoined rectangular neuston nets $(2 \times 1 \mathrm{~m}, 1 \mathrm{~mm}$ mesh and $0.5 \times 1 \mathrm{~m}, 150 \mu \mathrm{m}$ mesh) were used to sample the sea surface to $\sim 0.5 \mathrm{~m}$ depth. The combined-net approach allowed for the concurrent collection of large and small fish larvae and their potential prey. Both net systems were outfitted with flow meters to estimate water volume filtered. All larvae from the monthly surveys were caught between sunrise and sunset except 20 ind. caught no later than 33 min after sunset. All regular transect sampling was performed during daylight hours to minimize diel effects and allow additional physical sampling during the night. Plankton samples were fixed in $95 \%$ ethanol and at least $2 \mathrm{~d}$ later drained and refilled with $70 \%$ ethanol. No correction for length or weight change was made for larval billfishes or their prey due to logistical constraints of live sorting and a lack of appropriate published relationships.

Additional sampling was performed to (1) investigate diel variability, including vertical distributions, and (2) estimate the evacuation rate of gut contents. 
For the former, a single station near the Florida shelf was sampled every $3 \mathrm{~h}$ for $42 \mathrm{~h}$ (2 day-night cycles) in August 2003. Each sampling period included a neuston and MOCNESS tow as described above. To estimate evacuation rates, sampling occurred during 2 consecutive evenings near the Florida shelf in June 2005, beginning at sunset with a neuston net tow and following with MOCNESS tows (one net, double oblique to $15 \mathrm{~m}, \sim 15 \mathrm{~min}$ in length) at the approximate times of $0.5,1.5,2.5$ and $3.5 \mathrm{~h}$ post-sunset. The observation of empty guts in the early morning and the decline of contents after sunset indicated that billfish larvae, similar to many other taxa, only feed during daylight.

Laboratory data collection. Larval billfishes were sorted from plankton samples and identified to species using morphometrics and lower-jaw pigment patterns (Luthy et al. 2005) or by molecular techniques (Richardson et al. 2007). These recent developments in istiophorid larval identification allowed for 800 ind. to be identified to species, leaving 26 ind. unidentified, and thus excluded from species-specific analyses. Larval body lengths (BL) were measured through a Leica MZ12 stereomicroscope with a camera and image analysis software (Image Pro-Plus 4.5, Media Cybernetics). Body lengths were recorded as notochord length (pre-flexion) or standard length (post-flexion).

Gut contents were examined under a Leica MZ15 stereomicroscope by excising the entire alimentary canal with a microscalpel and minutien pins and, after transferring to a small amount of immersion oil, teasing out prey items. Prey were counted and identified to the lowest taxonomic level practical. The 2 dominant crustacean genera, Farranula (copepod) and Evadne (cladoceran), were analyzed only at the genus level, although of those identifiable to species, all Farranula were F. gracilis and almost all Evadne were E. tergestina (except 22 of 2924 that were E. spinifera). Most undamaged prey items were measured in length with an ocular micrometer (copepod prosome length, larval fish standard length, and longest dimension in all other prey), as length was observed to be the dimension most often intact. Highly consistent lengths for both Farranula and Evadne allowed for the assignment of lengths to some individuals, including those damaged or deformed (amounting to $28 \%$ of these prey). Assigned lengths were the means of ingested individuals from their respective cruises and, for Farranula, were usually gender-specific.

Since no length to dry weight (L:DW) relationship is published for any Evadne species, and to avoid using extrapolated and potentially inappropriate relationships, we established L:DW equations for E. tergestina. For consistency, a relationship was also established for Farranula gracilis. For E. tergestina, 3 replicates of 50 ind. from each of 3 length classes were dried at $55^{\circ} \mathrm{C}$ for at least $3 \mathrm{~d}$ and weighed on a Cahn C-35 microbalance after attaining constant weights at room temperature. A linear regression of transformed mean lengths $(\mu \mathrm{m})$ and weights $(\mu \mathrm{g})$ for each of the 9 subsamples was established ( $\ln W=2.77 \ln L-17.27, \mathrm{r}^{2}=0.99$ ). The same method was used for adult F. gracilis, but due to distinct sexual dimorphism in size, 3 replicates of 50 ind. per sex were utilized $(\ln W=2.88 \ln L-17.39$, $\mathrm{r}^{2}=0.99$ ). Ingested larval fish prey were not converted to dry weight due to (1) identification and measurement being possible only on approximately half of the relatively intact larvae, and (2) morphological differences between prey taxa. For a subset of sailfish larvae, we established a body length (mm) to gut-free dry weight $(\mathrm{mg})$ relationship (BL:GFDW; GFDW = $0.005 \mathrm{BL}^{2.62}, \mathrm{n}=69, \mathrm{r}^{2}=0.91$ ). Gut-free weight was used as observed gut content weights often approached $25 \%$ of total body weight.

Prey availability estimates were made by subsampling a known volume of plankton sample with a Hensen-Stempel pipette and enumerating Evadne tergestina, Farranula gracilis and calanoid copepodids (juveniles and adults). Subsampling continued until at least 100 ind. per class had been recorded (Postel et al. 2000) or until 3 subsamples had been quantified (amounting to at least $1.5 \%$ of the sample).

Ontogeny of the gastrointestinal tract of sailfish larvae was examined histologically in 6 ind. (3.5 to $13 \mathrm{~mm}$ BL) preserved in a $4 \%$ formalin-seawater solution, specifically noting the development of gastric glands in the stomach, which allow for the efficient extracellular breakdown of proteins (Govoni et al. 1986a). For slide preparation, larvae were embedded in paraffin and $5 \mu \mathrm{m}$ frontal sections were stained with hematoxylin and eosin.

Data analysis. Feeding descriptors included feeding incidence, defined as the proportion of larvae with food present in the gut, and a similar value for the incidence of piscivory. Prey-type data included the percentage by number of all prey extracted $(\% \mathrm{~N})$ and the frequency within feeding larvae that the prey type occurred (\%FO). A commonly calculated index of relative importance was avoided due to inherent bias when (1) a diet is of either many small prey or a few large prey, as observed herein, and (2) values are assigned to broad larval size classes that are influenced by both ontogenetic changes in diet and the length-frequency distribution of the larvae inspected.

Variability in gut fullness was analyzed for billfish larvae $<7 \mathrm{~mm}$ BL containing only Farranula and/or Evadne prey ( $\mathrm{n}=393$ ), since these prey accounted for $90 \%$ of ingested items. This allowed for analysis by gut content weight without utilizing potentially inappropriate prey L:W conversions. Analyses were performed via ANOVA on values of relative gut content weight 
(relGCW, a proxy for gut fullness; calculated as prey DW as a percentage of predator GFDW) to examine the variability with time of day, larval length, season, region, year and species. Due to seasonal differences in day length, time of day collected was converted to a percentage of daylight elapsed relative to daylight length (relTOD). Larvae were grouped in bins of $10 \%$ relTOD and $1 \mathrm{~mm}$ length classes. A multiway ANOVA compared the random factors of year, time of year, region and predator species, without the significantly different 90 to $100 \%$ relTOD and 2 to $3 \mathrm{~mm}$ BL larvae (see 'Results'). Region comprised 2 groups of stations: the western portion of the SOF (Stns 1 to 9; faster current and higher primary productivity), and the eastern region (Stns 10 to 17; slower current and lower productivity). Time of year groupings were early season (Jun to Aug), including the observed peak in larval billfish abundance, and late season (Sep to Oct). Factor interactions were tested and removed from analyses due to nonsignificance. RelGCW values were $\log _{10}(x+1)$ transformed, and analyses were performed on values from individual larvae with the assumption of independence, since larval billfish abundances were very low relative to prey abundances and no correlation between larval abundance and mean relGCW for station samples was observed. The BL:GFDW relationship obtained for sailfish was used for both species with the assumption of similar larval morphology at these early stages (Luthy et al. 2005).

Prey selectivity analyses (following Manly et al. 2002) utilized prey proportions consumed and available to calculate the selection ratio:

$$
w_{i}=o_{i} / \pi_{i}
$$

where $o_{i}$ is the proportion of prey type $i$ consumed and $\pi_{i}$ is the proportion in the environment. Values $>1$ indicate selection for a prey type while values $<1$ indicate selection against a prey type. Selection ratios are near 1 when consumed proportions reflect those of the environment. Confidence intervals (Bonferroni-adjusted) used:

$$
\operatorname{SE}\left(w_{i}\right)=\sqrt{ }\left[o_{i}\left(1-o_{i}\right) /\left(u_{+} \pi_{i}^{2}\right)\right]
$$

where $u_{+}$is the total number of prey items consumed. Significant selection for or against a prey type was shown by CI not overlapping with 1 . Analyses were performed for the dominant prey, Farranula and Evadne, for a subset of 10 neuston samples representing a broad range of ingested-prey ratios. Selectivity values were calculated for individual samples, pooling prey consumed by all billfish larvae from each sample. The selection ratio (or forage ratio) was chosen due to its simplicity and statistical testability, although CIs are questionable when consumed prey are $<5$ in any category (Manly et al. 2002). The selection ratio becomes
Chesson's $\alpha$ (Chesson 1978) when expressed as a proportion of the sum of selection ratios and is similarly vulnerable to sampling error when prey are rare in the environment (Lechowicz 1982).

The decline in mean relGCW of larvae obtained during the evacuation rate study was used in conjunction with daytime relGCW values to estimate daily rations. Evacuation models describe the change of stomach contents, $S$, as:

$$
\frac{\mathrm{d} S}{\mathrm{~d} t}=-a S^{b}
$$

where $a$ is estimated and $b$, usually ranging from 0 to 1 , is often assumed or can be estimated generally by fit or specifically with nonlinear regression techniques. The most common daily ration models incorporate linear evacuation $(b=0$; Bajkov 1935, Canino et al. 1991, Bochdansky \& Deibel 2001) or exponential evacuation $(b=1$; Elliot \& Persson 1978, Eggers 1979), but square-root evacuation models $(b=0.5)$ have also been appropriate, and possibly more so than described (Jobling 1981, Andersen 1998; but see Persson 1986). Additionally, the general model of Pennington (1985), a Bajkov-like model similar to the modification of Eggers (1979), allows for the use of an estimated value of $b$ for daily ration estimation. As an alternative to assuming a single evacuation model, the data from the evacuation rate experiment were combined with several models and scenarios to better elucidate the effects of evacuation and daily ration model choice on the estimate of daily rations. All evacuation rate regressions were performed on untransformed means, as the use of transformed relGCW values was noted to overestimate daily ration estimates by as much as $30 \%$. Nonlinear regression parameters were estimated using the Marquardt method (NLIN procedure, SAS Institute) for each model, with $b$ either fixed or estimated (using Eq. 3 of Andersen 1998). Larvae utilized in these analyses were sailfish 3 to $6 \mathrm{~mm}$ BL (minimizing ontogenetic differences) containing Farranula only ( $\mathrm{n}=49 ; 85 \%$ of the larvae collected). Abundances of larger, piscivorous larvae were too low after sunset for separate analyses.

\section{RESULTS}

\section{Distribution, feeding incidence and diet}

Inspected larvae comprised 452 sailfish and 341 blue marlin, each with similar size ranges of 2 to $23 \mathrm{~mm} \mathrm{BL}$ and ca. $50 \%$ of the individuals $<4 \mathrm{~mm} \mathrm{BL}$. Only 7 white marlin Tetrapturus albidus were inspected and 26 istiophorids remained unidentified. Higher numbers of inspected sailfish were collected from the western 


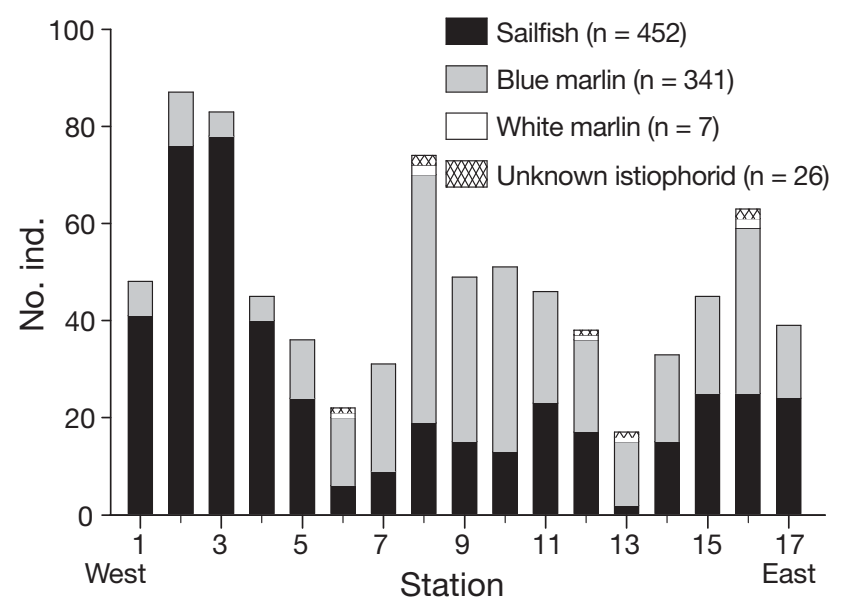

Fig. 2. Spatial distribution of inspected larval sailfish Istiophorus platypterus, blue marlin Makaira nigricans, white marlin Tetrapturus albidus and unidentified istiophorids across the Straits of Florida. Stations are numbered west to east, from the Florida shelf break to the Great Bahama Bank

region of the SOF, while blue marlin were more abundant in the central and eastern regions (Fig. 2). This pattern held for the total catch of these species (D. Richardson et al. unpubl. data). Vertically, $74 \%$ of the inspected larvae were collected at the sea surface with the neuston net and $26 \%$ were collected subsurface with the MOCNESS (with only $1 \%$ in depth intervals below $25 \mathrm{~m}$ ). The diel dynamics of the vertical distribution (Fig. 3) indicate that larval istiophorids avoid the sea surface during the night.

The feeding incidence for all istiophorid larvae was 0.94 (Table 1). Of the sailfish larvae collected at least $30 \mathrm{~min}$ after sunrise, the smallest ( 2 to $3 \mathrm{~mm} \mathrm{BL}$ ) and largest (8 to $21 \mathrm{~mm} \mathrm{BL}$ ) subgroups had lower feeding incidences (0.79 and 0.85 , respectively) than the 0.99
Table 1. Feeding incidence (proportion of larvae with prey present in gut) for all istiophorid larvae collected between sunrise and shortly after sunset, and for length classes of sailfish and blue marlin collected after $30 \mathrm{~min}$ post-sunrise. Values taken after 30 min post-sunrise minimize bias due to time of day collected, as larvae were observed to be daylight-only feeders. Illustrating this was the lower feeding incidence of larvae collected 0 to 30 min post-sunrise in conjunction with nighttime collections and evacuation rate sampling

\begin{tabular}{|lrc|}
\hline & $\mathrm{n}$ & $\begin{array}{r}\text { Feeding } \\
\text { incidence }\end{array}$ \\
\hline All istiophorid larvae & 826 & 0.94 \\
$\quad$ Sailfish & 452 & 0.90 \\
Blue marlin & 340 & 0.98 \\
White marlin & 7 & 1.00 \\
Collected > 30 min post-sunrise & & \\
Sailfish & & \\
$2-3 \mathrm{~mm}$ & 89 & 0.79 \\
3-8 mm & 296 & 0.99 \\
$8-21 \mathrm{~mm}$ & 41 & 0.85 \\
Blue marlin & 62 & 0.97 \\
$2-3 \mathrm{~mm}$ & 220 & 0.99 \\
3-8 mm & 49 & 1.00 \\
8-23 mm & & \\
Collected 0-30 min post-sunrise & 36 & 0.44 \\
All species & & \\
\hline
\end{tabular}

value for the intermediate 3 to $8 \mathrm{~mm}$ BL class. Nearly all blue marlin (0.97) larvae contained food, including the 2 to $3 \mathrm{~mm}$ BL class, which includes first-feeding larvae as indicated by comparison with identified yolksac larvae and the 2 to $3 \mathrm{~d}$ ages of larvae this size (Sponaugle et al. 2005).

Of 6159 prey items extracted from all larvae, the copepod Farranula and the cladoceran Evadne accounted for nearly $90 \%$ (Table 2). Frequencies of occurrence of Evadne were $55 \%$ for sailfish and $72 \%$ for blue marlin, while frequencies of Farranula approached $70 \%$ for both species. Farranula contributed $70 \%$ of the total dry mass of Farranula and Evadne combined, as female Farranula are approximately twice the weight of the average Evadne (and male Farranula). Other prey of less importance were Corycaeus copepods and Limacina pteropods (both more common at western stations, Fig. 4). Larval fish prey $\% \mathrm{~N}$ and $\% \mathrm{FO}$ were low due to their larger size and presence in the diet only at larger predator lengths; thus, these indices are not indicative of larval fish prey importance. The 7 identified white marlin had diets similar to sailfish and blue marlin, with Farranula contributing $70 \%$ and Evadne $22 \%$ of the 69 prey items extracted.
Fig. 3. Diel vertical distribution of istiophorid larvae during a $45 \mathrm{~h}$ study with $3 \mathrm{~h}$ sampling intervals. Relative abundance values are larval concentrations (larvae $\mathrm{m}^{-3}$ ) expressed as proportions of the sum of concentrations for the entire study within each depth interval. A neuston net and a MOCNESS were used for sea surface and subsurface sampling, respectively. All subsurface larvae were collected in the 1 to $25 \mathrm{~m}$ depth interval. Shaded areas indicate periods of darkness 
Table 2. Istiophorus platypterus and Makaira nigricans. Ingested prey items summarized by numerical percentage $(\% \mathrm{~N})$ and the frequency of occurrence in feeding larvae (\%FO). Raw numbers of prey are in parentheses for infrequent prey types and $\mathrm{n}$ is the total number of prey items excised

\begin{tabular}{|c|c|c|c|c|}
\hline \multirow[t]{2}{*}{ Prey } & \multicolumn{2}{|c|}{ Sailfish } & \multicolumn{2}{|c|}{ Blue marlin } \\
\hline & $\begin{array}{c}\% \mathrm{~N} \\
(\mathrm{n}=2687)\end{array}$ & $\% \mathrm{FO}$ & $\begin{array}{c}\% \mathrm{~N} \\
(\mathrm{n}=3134)\end{array}$ & $\% \mathrm{FO}$ \\
\hline Tintinnida & $0.07(2)$ & 0.25 & - & - \\
\hline Foraminifera: Globigerina & - & - & $0.03(1)$ & 0.30 \\
\hline \multicolumn{5}{|l|}{ Gastropoda } \\
\hline Thecosomata: Limacina & 2.72 & 5.16 & 0.73 & 3.90 \\
\hline Prosobranchia: Atlantidae & - & - & $0.03(1)$ & 0.30 \\
\hline Unknown dextral & $0.19(8)$ & 1.23 & - & - \\
\hline Cladocera: Evadne & 53.3 & 54.8 & 42.1 & 72.1 \\
\hline \multicolumn{5}{|l|}{ Copepoda } \\
\hline Farranula & 32.0 & 69.5 & 51.2 & 70.1 \\
\hline Corycaeus & 7.55 & 28.5 & 2.11 & 16.2 \\
\hline Oncaea & $0.11(4)$ & 0.74 & - & - \\
\hline Unknown corycaeid & $0.15(4)$ & 0.74 & $0.10(4)$ & 0.90 \\
\hline Calanoid & $0.33(9)$ & 1.47 & $0.19(6)$ & 0.90 \\
\hline Harpacticoid & $0.04(1)$ & 0.25 & - & - \\
\hline Nauplius & $0.22(6)$ & 1.23 & $0.35(12)$ & 1.80 \\
\hline Unknown copepod & 0.45 & 1.97 & 0.22 & 1.80 \\
\hline Ostracoda & $0.04(1)$ & 0.25 & $0.03(1)$ & 0.30 \\
\hline Amphipoda & - & - & $0.03(1)$ & 0.30 \\
\hline Larval fish & 1.97 & 10.6 & 2.14 & 15.0 \\
\hline Unknown crustacean remains & 0.82 & 4.91 & 0.64 & 4.20 \\
\hline Unknown & $0.04(1)$ & 0.25 & $0.06(2)$ & 0.60 \\
\hline
\end{tabular}

\section{Diet variability, prey selectivity and gut fullness}

Billfish diets changed little with early ontogeny (Figs. 4a,c). First-feeding larvae of both sailfish and blue marlin within the 2 to $3 \mathrm{~mm}$ BL class consumed the same prey as larger larvae, and generally lack a naupliusfeeding stage. The only ontogenetic shift was the inclusion of piscivory at ca. $5 \mathrm{~mm}$ BL (corresponding with flexion of the urostyle), which added to a diet of Farranula and Evadne until larval fish prey were exclusive at later stages. The increase in proportions of Farranula consumed with blue marlin size appears to be due to higher numbers of larger larvae collected from the central stations, where greater proportions of Farranula were consumed (Fig. 4d), and more smaller larvae collected in the east. Higher proportions of Evadne in sailfish are partially influenced by time of year since numbers of Evadne consumed were higher in the early summer, overlapping more with the occurrence of sailfish larvae

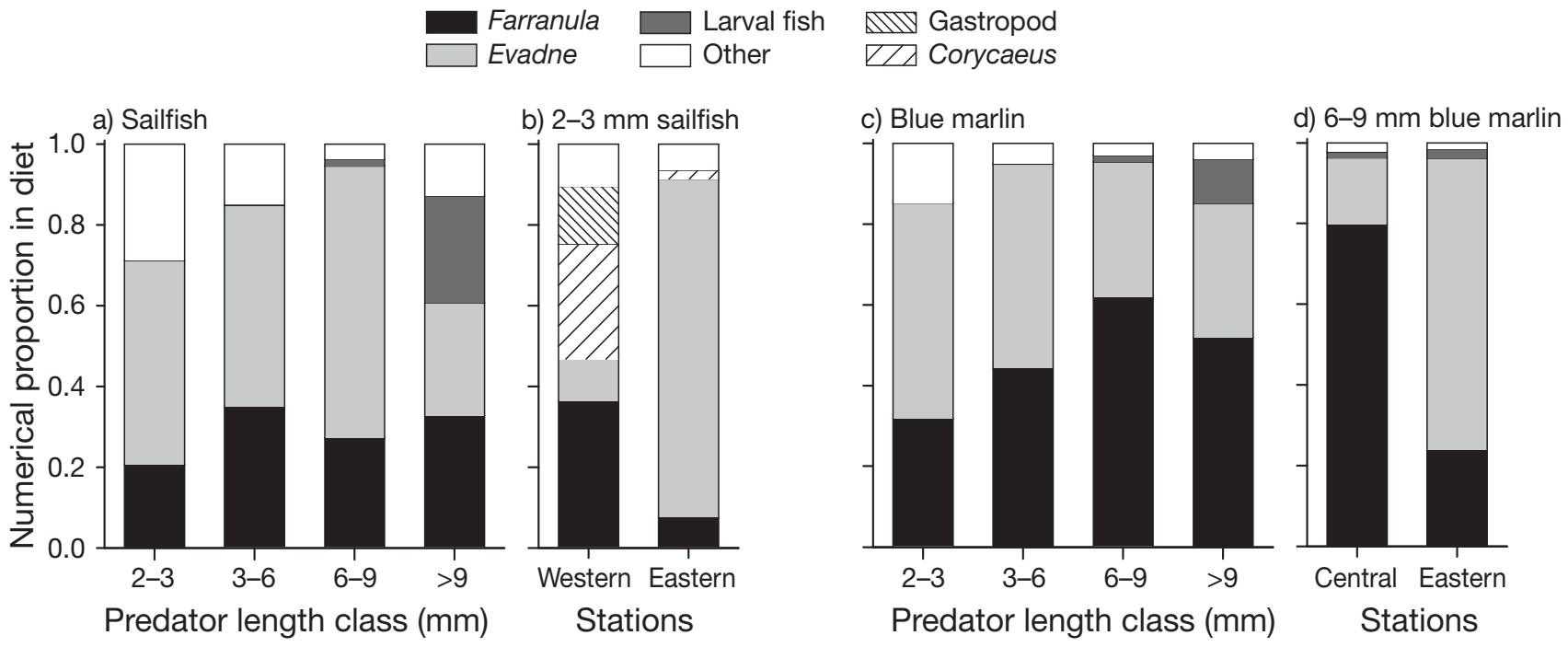

Fig. 4. Istiophorus platypterus and Makaira nigricans. Numerical proportions of ingested prey types with larval growth for (a,b) sailfish and (c,d) blue marlin. (b) shows the 2 to $3 \mathrm{~mm}$ body length (BL) sailfish in more detail than in (a): western and eastern stations are shown separately, and the 'Other' category is subdivided. Spatial differences, not capability, appear to explain the 'Other' category, which largely consists of Corycaeus copepods and gastropods. (c) For blue marlin, the increase in Farranula with larval size is a spatial effect of larval catch differences, illustrated by (d), which shows the 6 to 9 mm BL larvae in more detail, with differing proportions of Farranula and Evadne between the central and eastern regions of the Straits of Florida. Station numbers for (b), western: 1 to 6, eastern: 9 to 17. Station numbers for (d), central: 6 to 9, eastern: 11 to 15. 'Other' category in (a), (c) and (d) includes Corycaeus and gastropods 
Table 3. Istiophorus platypterus and Makaira nigricans. Dynamics of larval piscivory, including the smallest larva with evidence of piscivory, proportional incidence of piscivory, identifiable prey taxa and proportions of total, and mean larval prey lengths (expressed as a proportion of predator length). Numbers of larvae examined are in parentheses. Largely intact prey larvae were identifiable to at least family level for 25 of 55 sailfish prey and 39 of 67 blue marlin prey

\begin{tabular}{|c|c|c|}
\hline & Sailfish & Blue marlin \\
\hline Smallest piscivore & $5.0 \mathrm{~mm} \mathrm{BL}^{\mathrm{a}}$ & $5.1 \mathrm{~mm} \mathrm{BL}$ \\
\hline \multicolumn{3}{|l|}{ Incidence of piscivory } \\
\hline $6-8 \mathrm{~mm} \mathrm{BL}$ & $0.30(47)$ & $0.36(39)$ \\
\hline 8-10 mm BL & 0.85 (13) & $0.82(22)$ \\
\hline $10-18 \mathrm{~mm} \mathrm{BL}$ & $0.86(21)$ & $1.00(25)$ \\
\hline \multicolumn{3}{|c|}{ Prop. of identifiable prey larvae } \\
\hline Myctophidae & 0.04 & 0.08 \\
\hline Exocoetidae & 0.12 & - \\
\hline Hemiramphidae & 0.20 & - \\
\hline Holocentridae & 0.04 & 0.05 \\
\hline Carangidae & 0.12 & - \\
\hline Gerreidae & 0.04 & 0.05 \\
\hline Mullidae & 0.24 & 0.05 \\
\hline Gempylidae & - & 0.18 \\
\hline Scombridae (total) & 0.20 & 0.49 \\
\hline Thunnus spp. & 0.12 & 0.33 \\
\hline Katsuwonus pelamis & - & 0.03 \\
\hline Unidentifiable & 0.08 & 0.13 \\
\hline Istiophoridae & - & 0.10 \\
\hline Mean larval prey length & 0.52 & 0.53 \\
\hline Maximum observed & 0.88 & 0.68 \\
\hline \multicolumn{3}{|c|}{$\begin{array}{l}\text { a Two piscivorous sailfish larvae, each } 4.4 \mathrm{~mm} \mathrm{BL} \text {, were } \\
\text { collected during the } 2005 \text { evacuation rate study }\end{array}$} \\
\hline
\end{tabular}

in the SOF (Apr to Nov) and less so with that of blue marlin (Jul to Nov). A large 'other' prey category for 2 to $3 \mathrm{~mm} \mathrm{BL}$ sailfish (Fig. 4a) results from a greater abundance of smaller larvae in the western region where Corycaeus copepods and Limacina pteropods are more common prey (Fig. 4b).

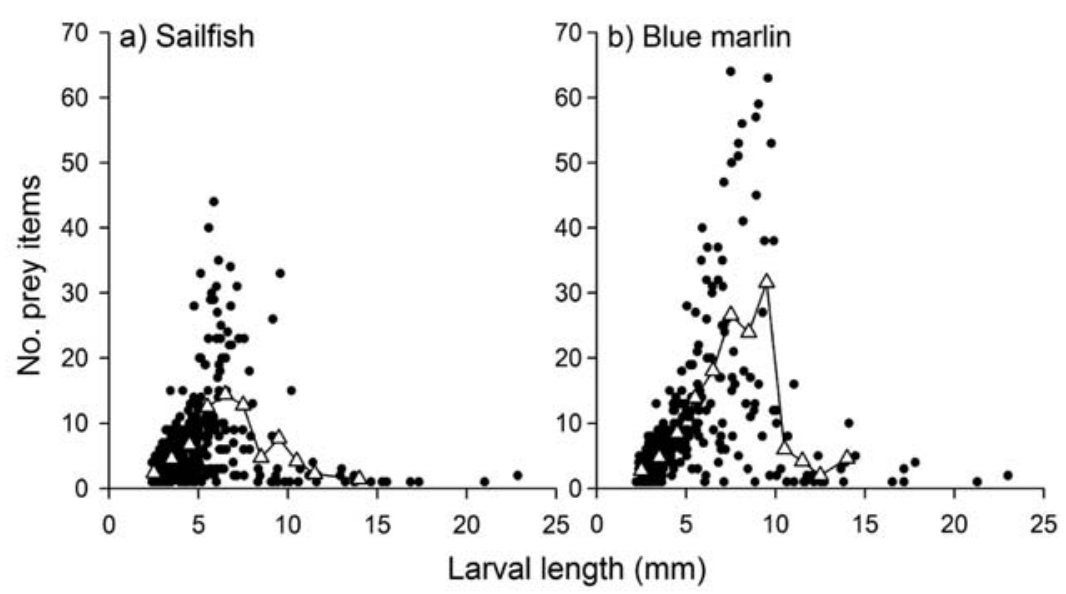

Fig. 5. Istiophorus platypterus and Makaira nigricans. Relationship between number of prey items per larva and larval predator length for (a) sailfish and (b) blue marlin. ๑: individual larvae; $\Delta$ : size-class means

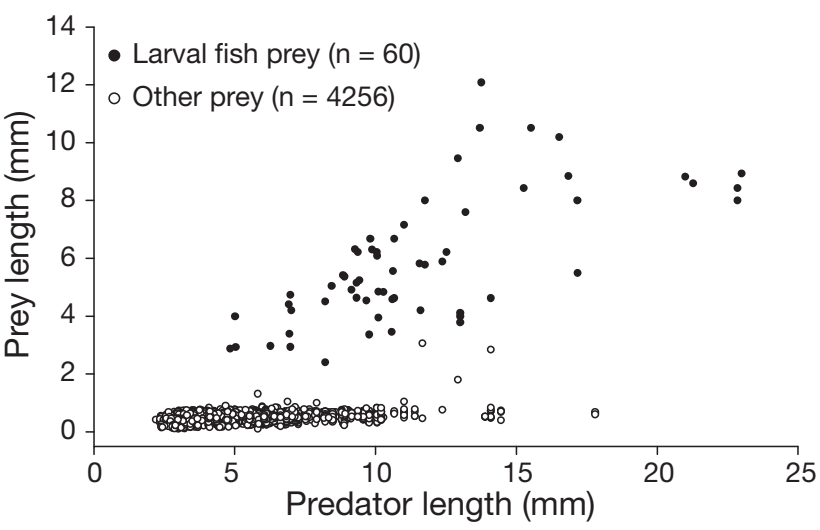

Fig. 6. Relationship between individual ingested prey length and larval istiophorid predator length

The incidence of piscivory increased with size as larger larvae became more exclusively piscivorous (Table 3). This was illustrated by an increase in prey numbers with larval size (Fig. 5) until a decline occurred when relatively large larval fish prey replaced numerous small Farranula and Evadne. Blue marlin had a higher peak in prey numbers at size with 9 larvae of 7 to $10 \mathrm{~mm} \mathrm{BL}$ containing over 50 prey items each (Fig. 5b). With piscivory being the only change in diet, the relationship of prey size to predator size shows an increase in prey size only for larval fish prey (Fig. 6).

Approximately half of the extracted larval fish prey were identifiable to at least the family level (Table 3), and these prey reflected the spatial variability of the predators (Fig. 3). Larval fish prey of sailfish were largely dominated by coastal pelagics (Exocoetidae, Hemiramphidae and Carangidae) and the coral reef fish family Mullidae. Blue marlin larval prey were mostly tunas (Scombridae), especially Thunnus spp., and snake mackerels (Gempylidae). Four larval prey of blue marlin were istiophorids, one of which had a larval tuna in its gut, in this instance placing the $23 \mathrm{~mm} \mathrm{BL}$ predator at perhaps the fifth trophic level.

Temporally, proportions of Farranula and Evadne consumed were variable and unpredictable, often switching dominance from month to month even at the same station (not shown). Spatially, however, there was an overall and common monthly trend for greater numbers and biomass of Farranula to be consumed towards the west while Evadne composed the majority at several eastern stations (Fig. 7).

Of the 2 dominant prey, Evadne was consumed in greater proportions than available in the plankton, while Farranula was consumed in smaller proportions (Table 4). Selection for Evadne and 

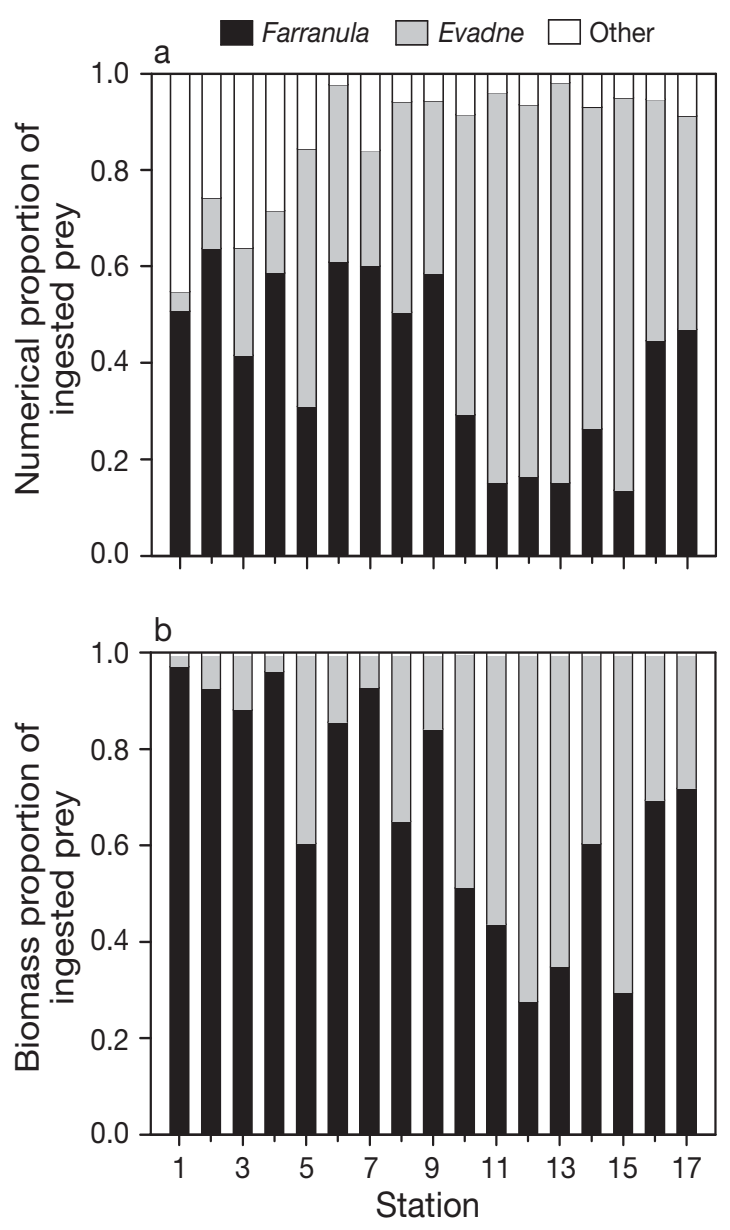

Fig. 7. Spatial distribution of (a) numerical, and (b) biomass proportions of ingested prey across the Straits of Florida for all billfish larvae. Biomass proportions are from converted dry weight and only include proportions of the total of the dominant prey types Farranula and Evadne

Table 4. Prey selectivity analysis and environmental prey concentrations for 10 samples collected in 2004. Numbers of prey excised from larval billfishes are indicated by $u_{F}$ for Farranula (Farr.) and $u_{E}$ for Evadne. Significant selection for $\left(w_{i}>1\right)$ or against $\left(w_{i}<1\right)$ (see Eq.1) a prey type is denoted by asterisks, all at $\mathrm{p}<$ 0.001 . No calanoid copepodids were consumed despite relatively high concentrations (conc.) available in the environment (env.) Stn = station number

\begin{tabular}{|c|c|c|c|c|c|c|c|c|}
\hline \multirow[b]{2}{*}{ Date } & \multirow[b]{2}{*}{ Stn } & \multirow[b]{2}{*}{$u_{F}$} & \multirow[b]{2}{*}{$u_{E}$} & \multirow[b]{2}{*}{ Farr. } & \multirow{2}{*}{$W_{i} \overline{\text { Evadne }}$} & \multicolumn{3}{|c|}{ —Env. conc. $\left(\mathrm{m}^{-3}\right)$} \\
\hline & & & & & & Farr. & Evadne & Calanoid \\
\hline Jun & 5 & 9 & 57 & $0.36^{*}$ & $1.38^{*}$ & 25 & 41 & 118 \\
\hline Jun & 10 & 4 & 77 & $0.10^{*}$ & $1.82^{*}$ & 50 & 55 & 126 \\
\hline Jun & 16 & 27 & 6 & 0.87 & 3.03 & 116 & 7 & 201 \\
\hline Jul & 16 & 4 & 22 & $0.25^{*}$ & $2.16^{*}$ & 254 & 164 & 150 \\
\hline Aug & 10 & 35 & 38 & $0.56^{*}$ & $3.81^{*}$ & 129 & 20 & 95 \\
\hline Aug & 11 & 3 & 76 & $0.13^{*}$ & $1.38^{*}$ & 327 & 749 & 399 \\
\hline Sep & 8 & 8 & 136 & $0.12^{*}$ & $1.82^{*}$ & 45 & 49 & 311 \\
\hline Sep & 9 & 44 & 172 & $0.26^{*}$ & $3.53^{*}$ & 245 & 72 & 351 \\
\hline Oct & 6 & 27 & 3 & 0.94 & 2.17 & 113 & 5 & 332 \\
\hline Oct & 8 & 127 & 3 & 0.99 & 1.71 & 279 & 4 & 482 \\
\hline
\end{tabular}

against Farranula was significant for 7 samples $(\mathrm{p}<$ 0.001). The 3 other samples showed the same trend but the influence of low Evadne concentrations precluded significant selection. Calanoid copepodids, which were of similar sizes and up to 3 times more abundant than Farranula and Evadne combined, were not consumed by any larvae. The pattern of consistent selection for Evadne and against Farranula also held for individual larvae for both sailfish and blue marlin. The possibility for vertical distribution bias is minimal, since all larvae and prey for these analyses were collected only from the upper $0.5 \mathrm{~m}$ of the water column.

Relative gut content weight (relGCW) with time of day showed a significant increase in the last $10 \%$ of daylight for both years combined (Tukey HSD, all p < 0.001), a pattern observed each year (Fig. 8a). Additionally, the sunset mean near $20 \%$ relGCW in the evacuation rate study may indicate a more pronounced evening peak closest to darkness. Significant differences in relGCW with larval length (Fig. 8b) were also observed, with the 2 to $3 \mathrm{~mm}$ BL class differing from all but the 6 to $7 \mathrm{~mm}$ BL size class (Tukey HSD, p $=0.03$ to 0.001). The nonlinearity of this relationship complicates analyses; yet with and without the 2 to $3 \mathrm{~mm}$ size class, there was a significant difference in relGCW between years, with 2004 values being higher than those in 2003 (Table 5, Fig. 8a). There were no differences in relGCW between seasons, regions or species (Table 5).

\section{Gut evacuation, daily ration and ontogeny}

Relative gut content weight declined after sunset until complete gastric evacuation occurred in 3 to $4 \mathrm{~h}$ (Fig. 9). Ambient water temperature was $30.6^{\circ} \mathrm{C}$. Including the $3.5 \mathrm{~h}$ postsunset collection when 8 of 10 larvae were empty, the best general model describing evacuation was the squareroot model $(b=0.5)$, as the estimation of $b$ yielded a value of 0.44 . Excluding the $3.5 \mathrm{~h}$ time period, which may be more appropriate (Bochdansky \& Deibel 2001), the decline was linear. Daily ration estimates differed substantially with model choice of both evacuation rate and daily ration (Table 6). The Pennington (1985) model estimated a daily ration of $75 \%$ GFDW during maximum daylight lengths of $14 \mathrm{~h}$, while use of the linear portion of the evacuation relationship and the approach of Bochdansky \& Deibel (2001) yielded a daily ration 


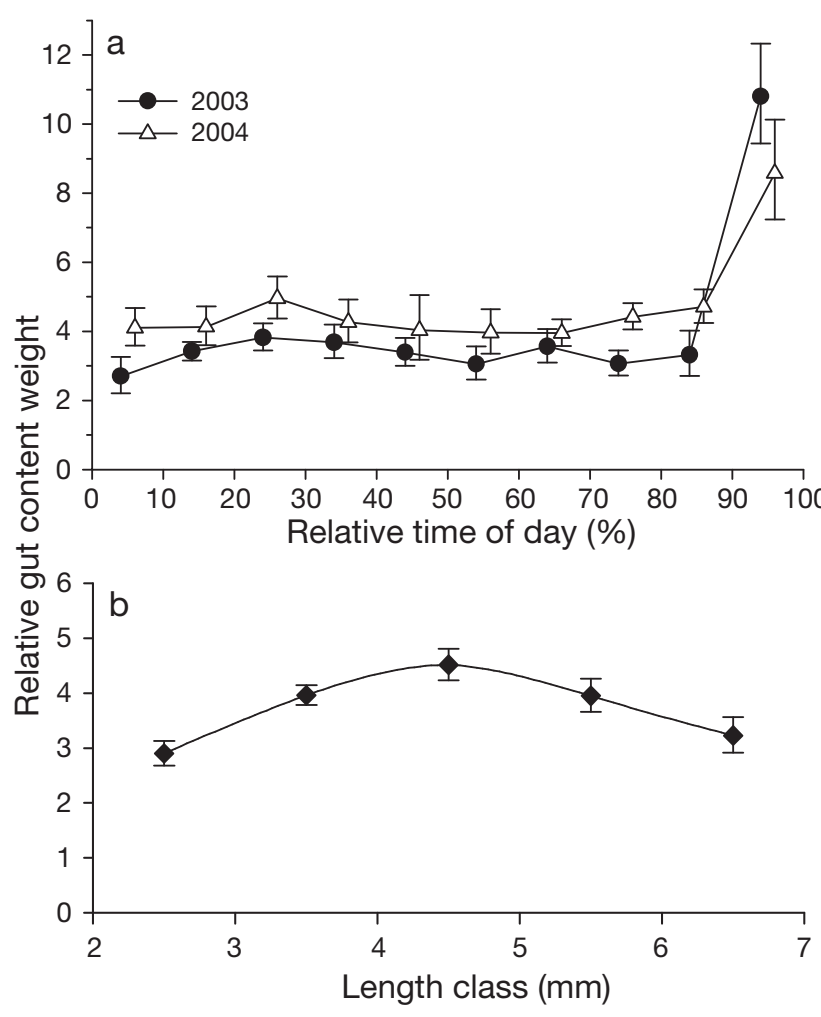

Fig. 8. Relationship between relative gut content weight (percentage of gut-free body weight) and (a) time of day ( $\mathrm{n}=393)$, and $(b)$ larval length $(n=368)$ for istiophorids. Data are backtransformed means $\pm \mathrm{SE}$ (from $\log _{10}[\mathrm{x}+1]$ ). Relative time of day (relTOD) is the percentage of daylight elapsed from sunrise to sunset. Data and analysis in (b) are for both years and exclude 90 to $100 \%$ relTOD

estimate of $34 \%$. Aside from model choice effects, daily rations were up to ca. $23 \%$ greater in June and July (14 h of daylight), a time of year when the peak of spawning is potentially occurring (D. Richardson et al. unpubl. data), than in November (11 $\mathrm{h}$ of daylight).

Table 5. Istiophorus platypterus and Makaira nigricans. ANOVA results investigating variability in gut fullness (estimated as relative gut content weight), with year, season, region in the Straits of Florida, and predator species. Only the same collection months each year (Jun to Oct) were included. The significantly different relative time of day prior to sunset and the 2 to $3 \mathrm{~mm}$ BL size class were excluded

\begin{tabular}{|lcccc|}
\hline Source & df & MS & $F$ & $p$ \\
\hline Year & 1 & 0.369 & 10.7 & 0.001 \\
Season & 1 & 0.017 & 0.49 & 0.49 \\
Region & 1 & 0.024 & 0.70 & 0.40 \\
Species & 1 & 0.000 & 0.001 & 0.97 \\
Residual & 268 & 0.034 & & \\
\hline
\end{tabular}

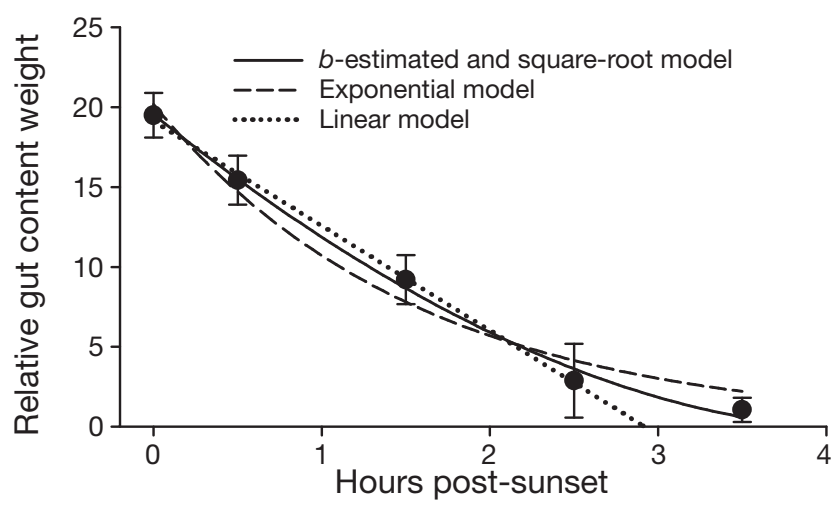

Fig. 9. Istiophorus platypterus. Mean $( \pm \mathrm{SE})$ relative gut content weight (percentage of gut-free body) vs. time post-sunset for larvae collected to estimate the rate of gut evacuation. Nonlinear regression lines are from models that describe the decline in contents with different values for the parameter $b$ (see 'Materials and methods' and Table 6 ). The $b$-estimated model $(b=0.44)$ and the square-root model $(b=0.5)$ essentially share the same regression line. The linear model excludes the $3.5 \mathrm{~h}$ collection (Bochdansky \& Deibel 2001). $\mathrm{n}=$ 49 , including 8 larvae containing no prey at $3.5 \mathrm{~h}$ post-sunset

Histological analyses of gastrointestinal tract ontogeny showed the early development of a blind sac, the enlargement of the stomach with gastric glands developing throughout the mucosa, and a corresponding decrease in relative intestinal volume (Fig. 10). Gastric glands were first observed in a $4.2 \mathrm{~mm}$ BL sailfish in the stomach's blind sac (Fig. 10a). The only smaller specimen examined (3.5 mm BL) had a much smaller blind sac without gastric glands.

\section{DISCUSSION}

\section{Feeding incidence, diet and ontogenetic diet shifts}

Larval istiophorid billfishes consistently exhibited a high feeding incidence over broad ontogenetic, temporal and spatial scales. Although the presence of prey alone does not preclude the possibility of suboptimal feeding and eventual starvation, high feeding incidence $(0.94$ overall and 0.79 to 0.97 for first-feeding larvae), in conjunction with rapid gut evacuation, indicates the likelihood that feeding by the larval population as a whole is frequent and successful. Extrapolating these results to levels of starvation mortality is not possible, but the ability to withstand an empty gut for 7 to $10 \mathrm{~h}$ during the night (a non-feeding period of 10 to $13 \mathrm{~h}$ ) suggests that empty guts during daytime should be present prior to larval death from starvation. High feeding incidences have been reported for a variety of species, including Indo-Pacific billfishes (Gorbunova \& 
Table 6. Evacuation rate and daily ration models used to estimate daily rations. Evacuation models were fit to data in Fig. 9 with parameter $b$ fixed or estimated (see Eq. 3). Daily ration estimates, as percent of gut-free body weight, given for minimum and maximum daylight lengths (duration of feeding) when billfish larvae are present during the protracted spawning season of approximately

\begin{tabular}{|c|c|c|c|c|}
\hline \multicolumn{2}{|c|}{ _ Gut evacuation__ } & \multicolumn{3}{|c|}{ Daily ration estimate $ـ$} \\
\hline Model & $b$ & Model & $11 \mathrm{~h}$ & $14 \mathrm{~h}$ \\
\hline \multirow[t]{2}{*}{ Linear } & \multirow[t]{2}{*}{0} & Canino et al. (1991) & 15.4 & 19.7 \\
\hline & & $\begin{array}{l}\text { Bochdansky \& Deibel (2001) } \\
\text { with Egqers (1979) }\end{array}$ & 29.3 & 34.3 \\
\hline \multirow[t]{2}{*}{ Exponential } & \multirow[t]{2}{*}{1} & Elliot \& Persson (1978) & 41.7 & 50.2 \\
\hline & & Eggers (1979) & 45.0 & 54.3 \\
\hline \multirow[t]{2}{*}{ Square-root } & \multirow[t]{2}{*}{0.5} & Thorpe (1977) & 44.5 & 49.4 \\
\hline & & Pennington (1985) & 59.4 & 72.6 \\
\hline$b$-estimated & 0.44 & Pennington (1985) & 61.5 & 75.3 \\
\hline
\end{tabular}
April to November

pods, and were also shown to do so selectively among many available prey types (Govoni et al. 1986b). Such diets differ from many other larval fishes that consume more diverse prey that are often dominated by calanoid copepods (e.g. Pepin \& Penney 1997). If broader diets are more prevalent in higher latitudes, larval fish diversity and the potential for competition may be low enough in these regions, especially during bloom periods, to make specific dietary niches unnecessary.

Many species of fish larvae consume copepod nauplii during the first feeding stage. However, larval billfishes are precocious at first feeding, possessing the mouth, sensory capability

Lipskaya 1975, Uotani \& Ueyanagi 1997), although they are often much lower in other taxa. For example, in the tropical Indian Ocean, only ca. 50\% of larval scombrids collected during daylight hours had prey present in the gut (Young \& Davis 1990). Possibly due to the extensive and protracted spawning by many species in lower latitudes, and the limited spatial and temporal scope of many studies, it has been difficult to infer how representative previously observed feeding incidence data are. However, with monthly sampling for $2 \mathrm{yr}$ in the SOF, the present study provides evidence that high feeding incidence may occur throughout the extended period of larval billfish presence.

Diets of larval billfishes were notably narrow, with Farranula copepods and Evadne cladocerans numerically dominating throughout early ontogeny. Such a narrow diet, as indicated by the selectivity analyses, was not a reflection of what was available since calanoid copepods usually occurred in higher concentrations than Farranula and Evadne. Farranula copepods may be a reliable resource, since they have been shown to occur year-round and have the highest reproductive activity of all copepods off Jamaica (Webber \& Roff 1995). IndoPacific larval billfishes had similarly narrow diets, consuming Evadne and Corycaeus copepods (Uotani \& Ueyanagi 1997). Adjacent to the SOF in the Gulf of Mexico, sciaenid larvae fed upon prey similar to those of billfishes, including cyclopoid copepods and Limacina ptero-

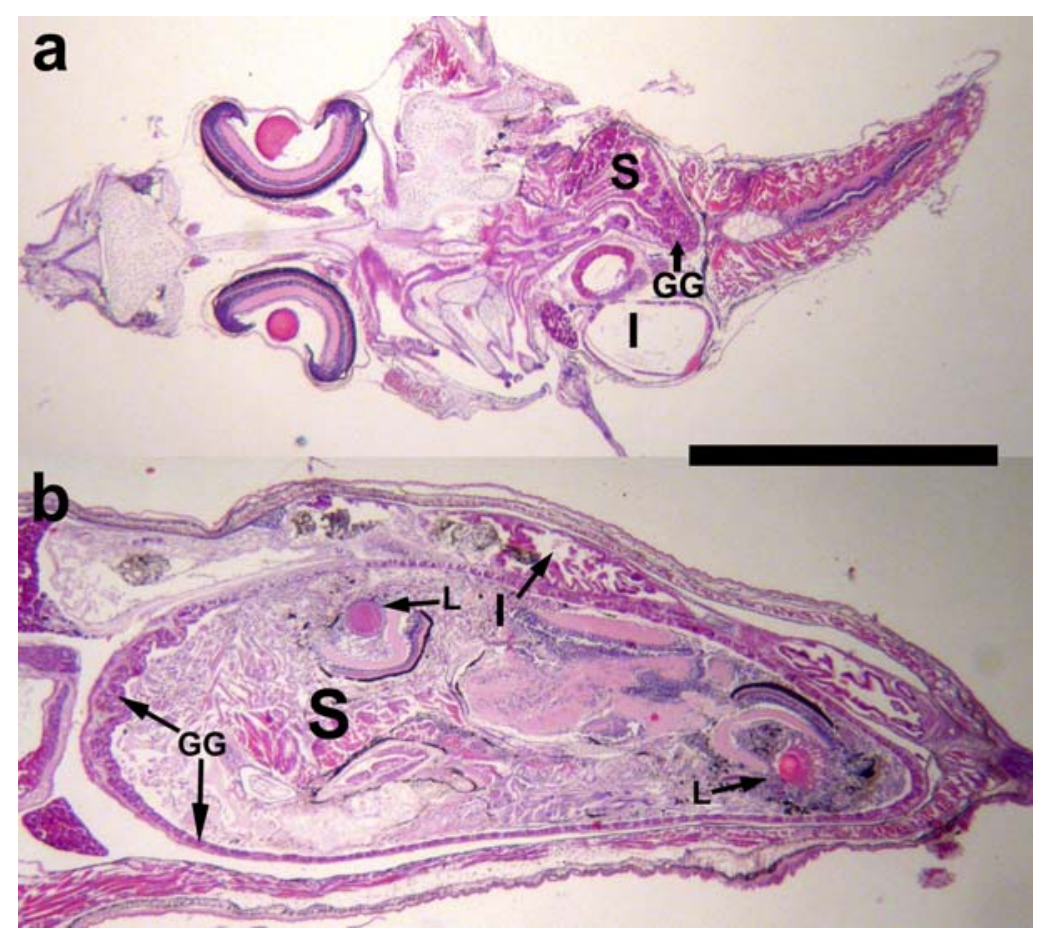

Fig. 10. Istiophorus platypterus. Frontal histological sections of (a) an entire $4.2 \mathrm{~mm}$ BL larva, and (b) the gastrointestinal region of a $13 \mathrm{~mm}$ BL larva. Gastric glands (GG) have developed in the posterior stomach (S) of the small larva and fully surround the stomach of the large larva that contains 2 ingested fish larvae, including the lenses (L) and surrounding eye. The relatively large intestine (I) in small larvae (containing a Farranula copepod in (a)) becomes relatively narrow along the margin of the coelom as the large stomach develops. Scale bar $=1 \mathrm{~mm}$ 
trary to many studies that show a more constant increase in prey size, usually including shifts from copepod eggs and nauplii to calanoid copepodids and larger adults (e.g. Anderson 1994, Pepin \& Penney 1997). Perhaps the most advanced first-feeding larvae are the coastal mackerels Scomberomorus spp. that are first-feeding piscivores (Shoji et al. 2001), a strategy presumably dependent upon higher larval fish prey abundances near the coast. For larval billfishes, the inclusion of piscivory was after a period of crustacean feeding (>5 mm BL) and complemented the crustacean diet until nearly exclusive at much greater lengths $(\sim 12 \mathrm{~mm} \mathrm{BL})$.

\section{Gut evacuation and daily ration}

The estimation of gut evacuation rates is possible with field or laboratory studies, each having advantages and disadvantages. The laboratory setting allows elimination of the potential slowing of gut passage times due to discontinuous feeding (Wuenschel \& Werner 2004); yet, it is unknown how these rates relate to those in the natural environment. As larval billfishes are difficult to maintain alive in the laboratory (Post et al. 1997), field efforts are currently the only option, and consequently daily rations may be underestimated. In addition to this limitation, it was shown that estimating daily rations may be less straightforward than often implied in the larval fish literature, and that estimates of daily rations can vary substantially depending on both evacuation and daily ration model choice. In this study, two evacuation models for larval sailfish appeared most appropriate, depending upon the inclusion of the last collection period ( $3.5 \mathrm{~h}$ post-sunset) in which 8 of 10 larvae were empty. Although it is often recommended to truncate data usage once empty guts appear, when these data were included, the best general model was the square-root model, as the estimated $b$ parameter in the decline of contents (0.44) was near 0.5 . With the daily ration model of Pennington (1985), consumption estimates were near $75 \%$ of GFDW per day, with $14 \mathrm{~h}$ of feeding. Without the $3.5 \mathrm{~h}$ period, evacuation was distinctly linear. Utilizing the approach of Bochdansky and Deibel (2001), termed the redefined linear model, daily rations were over $50 \%$ lower (34\% with $14 \mathrm{~h}$ of daylight). Such lower estimates than the non-linear approaches have been noted (Bochdansky \& Deibel 2001). For larval sailfish, a linear relationship may result from the use of converted weights (essentially ingestion = egestion, similar to the use of prey numbers) rather than actual remaining biomass; thus, the redefined linear model may be most appropriate. Earlier developed linear approaches (Bajkov 1935, Canino et al. 1991) appear to greatly underestimate daily rations for sailfish larvae (i.e. about half of the estimate is consumed in the last $10 \%$ of the day); this conclusion has also been drawn for other taxa (e.g. Hillgruber \& Kloppmann 2001).

One clear potential cause of daily ration variation is daylight length. Estimates for $14 \mathrm{~h}$ of feeding were substantially greater than those for an 11-h feeding period, which is experienced by larvae spawned late in the protracted spawning season of billfishes. The effect of water temperature on these differences is not accounted for, although monthly mean surface-water temperatures ranged from ca. 26 to $30^{\circ} \mathrm{C}$ during larval billfish occurrence. The cooler temperatures together with the shortest daylight lengths should only add to the seasonal difference in daily rations. Comparisons with other taxa are difficult due to the variety of approaches used; however, other work has estimated larval daily rations of 25 to $30 \%$ for oceanic tunas Thunnus spp. from the Indian Ocean (Young \& Davis 1990) and $\sim 120 \%$ for coastal, piscivorous Japanese Spanish mackerel Scomberomorus niphonius (Shoji et al. 2001). Laboratory efforts focused on estuarine species just inshore of the SOF yielded values near $50 \%$ when prey concentrations were held similar to the natural environment (Houde \& Schekter 1981). For comparative purposes, the greatest potential caveat in this and several studies is the use of preserved larvae and prey, which can influence estimates if effects of weight loss by preservation on predator and prey are not similar. Otherwise, for an evacuation rate, the approach used herein should be preferable due to the avoidance of using methods that include (1) an assumed evacuation rate, (2) the potentially unsuitable use of prey numbers without a correction for size, and (3) the linear fitting of transformed gut fullness data for parameter estimation instead of employing nonlinear techniques.

\section{Feeding variability and implications}

Aside from its role in starvation, feeding can influence total numbers of larval billfishes surviving to later stages if growth rates are reduced by suboptimal feeding (Houde 1987). Such an effect could be large since the annual egg production of blue marlin in the SOF is estimated to be in the trillions (D. Richardson et al. unpubl. data). This possibility is supported by differences in blue marlin larval growth between the SOF and nearby Exuma Sound (Sponaugle et al. 2005). The dynamics of piscivory in the present study may offer insight into how feeding could affect growth. Sailfish, more common along the western SOF, consumed a variety of larval fish prey, including coral reef fishes and coastal pelagics. With a more diverse and likely larger source population of spawning adults upstream 
along the Florida Keys, sailfish near the western shore may be less vulnerable to fluctuations in ichthyoplankton availability. In contrast, the majority of larval fishes consumed by blue marlin in the central SOF were of a few taxa, largely oceanic tunas and snake mackerels. The reliance upon a less diverse resource could mean greater vulnerability to factors affecting the abundance of prey larvae, including fluctuations in adult abundances or spawning times and locations (especially of tunas). Supporting evidence for potential mismatches between piscivorous blue marlin and prey larvae may be seen in the relationships of number of prey ingested and predator size (Fig. 5). The greatest number of prey items within a sailfish was 44 ; yet 9 blue marlin of piscivorous lengths collected in the central SOF contained 50 to 64 crustacean prey (predominantly Farranula) instead of larval fish prey. This peak indicates the likelihood of occasionally low larval fish prey abundances for piscivorous blue marlin. This is further supported by total larval fish abundances across the SOF showing that fish larvae are approximately twice as abundant in the western as in the central SOF (J. Llopiz et al. unpubl. data). Without linking growth and feeding, only the potential for growth effects can be noted, but direct relationships have been shown for piscivorous Japanese Spanish mackerel larvae (Shoji \& Tanaka 2006). Additionally, swordfish Xiphias gladius larvae exhibit a distinct increase in linear growth rates once piscivory begins (Govoni et al. 2003), and for istiophorids, the exponential growth of blue marlin and sailfish larvae (Sponaugle et al. 2005) is much faster at later, piscivorous lengths.

Evadne cladocerans were selected for in each of the samples analyzed for prey selectivity, but were commonly not consumed at many station-month combinations, indicating the likelihood of frequent unavailability. If larval billfishes select Evadne due to greater profitability (perhaps due to higher capture success, less handling time, or a higher energy to bulk ratio [e.g. Whelan \& Brown 2005]), the net result should be faster growth and thus higher overall survival when Evadne is available. If Evadne are actively selected for, such selection for smaller prey type generally contradicts optimal foraging theory and other work showing higher condition when feeding on larger prey (Anderson 1994). The alternative is that there may not actually be selection of Evadne over Farranula. If optimal foraging theory holds for larval billfishes such that less profitable prey are either always attacked upon encounter or never attacked (depending upon relative abundances; Stephens \& Krebs 1986), the inclusion of Farranula in diets throughout a broad range of abundances relative to Evadne may suggest that Evadne is not selected over Farranula. If so, the discrepancy between consumed and ambient proportions of
Evadne and Farranula could be due to factors such as greater capture success or detection distances for Evadne, or occurrence in micropatches or aggregations, for example at the air-sea interface. Furthermore, the term 'selectivity' may be less appropriate for larval billfishes, since prey concentrations are so low in these waters relative to a larva's search volume (Pepin \& Penney 1997), resulting in few simultaneous encounters with more than 1 prey type. Concentrations of Farranula and Evadne were <2 ind. $10 \mathrm{l}^{-1}$ in over half of the samples used in the selectivity analyses. Such low prey abundances contrast with the highly productive periods in higher latitudes during which prey can occur at concentrations of 100 to $>1000$ ind. $10 \mathrm{l}^{-1}$ (Hillgruber et al. 1995, Pepin \& Penney 1997).

The use of relative gut content weight (relGCW) as a proxy for gut fullness for larval billfishes helped account for the rapid increase in gut capacity with growth (Fig. 5), allowing for better resolution of the observed peak in feeding prior to sunset. This increase in feeding intensity significantly contrasted with relGCW values throughout the rest of the day, which were quite variable and ranged from near 0 to $13 \%$, illustrating not only greater filling of guts but also a synchrony of filling in the last part of the day. Prey availability data from these samples are unavailable; however, work on diel vertical migrations of both Farranula and Evadne indicates that abundances near the surface are actually lower at nighttime (Mullin \& Onbe 1992, Paffenhofer \& Mazzocchi 2003), suggesting this peak may not be due to an increase in prey availability. One possibility is that greater levels of polarized light during crepuscular periods enhance prey detection (Novales Flamarique \& Browman 2001). However, a similar peak in gut fullness near sunrise was not observed. If prey are not more abundant and there is no enhancement of prey detection or capture success, it may be possible that an optimal feeding rate exists during the day (e.g. allowing thorough digestion without unnecessary energy expenditure) with an increase and synchronization of feeding activity before a nightly non-feeding period. Although generally uncommon, evening peaks in gut fullness have also been shown in other taxa (Anderson 1994, Fortier \& Villeneuve 1996), but they are much less pronounced than those observed in this study for larval billfishes.

The differences in relGCW with size class may reflect a changing allometry of gut capacity with ontogeny, but more importantly draw attention to the potential influence such a difference may have on other analyses. Although the greatest difference in size-class means of relGCW was ca. $1.5 \%$ of larval weight, ignoring this difference and including the 2 to $3 \mathrm{~mm}$ BL size class in the analysis of temporal and spatial effects would have yielded an erroneous conclu- 
sion of significant seasonal differences in relGCW. In this situation, the greater relGCW in the late-season group would have been an artifact of the greater proportion of larger larvae collected during this time (i.e. fewer recently spawned 2 to $3 \mathrm{~mm}$ BL larvae).

Significantly greater gut fullness in 2004, independent of any ontogenetic influence, indicates the possibility of interannual differences in feeding conditions, which could translate to differences in growth and overall survival. Possibly due to temporal and spatial constraints of sufficient sampling, previous studies in tropical/subtropical waters have been unable to investigate interannual feeding variability. Similar studies in higher latitudes, which are also somewhat limited in interannual comparisons, are usually associated with the temporal match or mismatch of the feeding of fish larvae with secondary productivity peaks (e.g. Anderson 1994), or ignore feeding behavior altogether and only relate larval abundance peaks or recruitment levels to zooplankton peaks (e.g. Cushing 1990). Due to the narrow diet of larval billfishes, the use of general secondary production indices to infer feeding success may be inappropriate if Farranula, Evadne or larval fish prey do not follow the pattern of the zooplankton as a whole.

The trophic ecologies of larval sailfish and blue marlin are distinct from many taxa in both high and low latitudes. Attributes include a high feeding incidence, a narrow diet throughout ontogeny, highly selective feeding within a diverse prey environment, and the precocious ability to rely upon adult copepods at first feeding and then piscivory at lengths of $5 \mathrm{~mm} \mathrm{BL}$. Such behaviors are counterintuitive when considering the potential constraints of the subtropical oceanic SOF. The physical limitations in lower latitudes include shorter summertime daylight lengths and higher temperatures, resulting in less foraging time with an increase in metabolic activity and caloric demands. Biologically, low-latitude oceanic waters are oligotrophic and generally have low levels of productivity although the contributions of small crustaceans (Turner 2004) and the microbial food web (e.g. Landry 2002) are becoming better understood. Because of these constraints, the broad utilization of the lowlatitude open ocean as larval habitat by resident and migratory species (Johannes 1978, Bakun 1996) seems paradoxical; yet, this is the basis for hypotheses that implicate larval fish predation, not starvation, as driving the evolution of spawning strategies (Bakun \& Broad 2003). Although much remains unknown especially in other low-latitude regions, the successful feeding by larval billfishes despite the presumed constraints suggests that the Straits of Florida may be more conducive to larval fish survival than previously assumed.
Acknowledgements. This work would not have been possible without the assistance of D. Richardson, C. Guigand, A. Exum, L. Gundlach, A. Shiroza, P. Lane, K. Leaman, P. Vertes, S. Smith and many others who helped with cruises, sample sorting and other logistical support. Special thanks to D. Richardson and A. Exum for the genetic identification of many larvae and to the captain and crew of the RV 'F.G. Walton Smith'. J. Serafy provided statistical advice, and manuscript drafts were greatly improved by the comments of $\mathrm{M}$. Hauff, S. Smith and S. Sponaugle and 4 anonymous reviewers. Funding was provided by grants from the National Science Foundation (OCE-0136132) and the Gulf States Marine Fisheries Commission (Billfish-2005-017) to RKC, with additional support from a gift from Arthur B. Choate to the University of Miami's Billfish Research Program, the Harding Michel Memorial Fellowship, NOAA-LMRCSC, the Capt. Bob Lewis Billfish Challenge Scholarship, and the YCMBT/Capt. Harry Vernon, Jr. Scholarship.

\section{LITERATURE CITED}

Andersen NG (1998) The effect of meal size on gastric evacuation in whiting. J Fish Biol 52:743-755

Anderson JT (1994) Feeding ecology and condition of larval and pelagic juvenile redfish Sebastes spp. Mar Ecol Prog Ser 104:211-226

Bajkov AD (1935) How to estimate the daily food consumption of fish under natural conditions. Trans Am Fish Soc 65:288-289

Bakun A (1996) Patterns in the ocean: ocean processes and marine population dynamics. University of California Sea Grant, San Diego, in cooperation with Centro de Investigaciones Biológicas de Noroeste, La Paz, Baja California Sur, Mexico

Bakun A, Broad K (2003) Environmental 'loopholes' and fish population dynamics: comparative pattern recognition with focus on El Niño effects in the Pacific. Fish Oceanogr 12:458-473

Bochdansky AB, Deibel D (2001) Consequences of model specification for the determination of gut evacuation rates: redefining the linear model. Can J Fish Aquat Sci 58: 1032-1042

Canino MF, Bailey KM, Incze LS (1991) Temporal and geographic differences in feeding and nutritional condition of walleye pollock larvae Theragra chalcogramma in Shelikof Strait, Gulf of Alaska. Mar Ecol Prog Ser 79:27-35

Chesson J (1978) Measuring preference in selective predation. Ecology 59:211-215

Cowen RK, Paris CB, Srinivasan A (2006) Scaling of connectivity in marine populations. Science 311:522-527

Cushing DH (1990) Plankton production and year-class strength in fish populations: an update of the match/mismatch hypothesis. Adv Mar Biol 26:249-293

Eggers DM (1979) Comment on some recent methods for estimating food consumption by fish. J Fish Res Board Can 36:1018-1019

Elliott JM, Persson L (1978) The estimation of daily rates of food consumption for fish. J Anim Ecol 47:977-991

Fortier L, Villeneuve A (1996) Cannibalism and predation on fish larvae by larvae of Atlantic mackerel Scomber scombrus: trophodynamics and potential impact on recruitment. Fish Bull 94:268-281

Gehringer JW (1956) Observations on the development of the Atlantic sailfish Istiophorus americanus (Cuvier) with notes on an unidentified species of istiophorid. Fish Bull $57: 139-171$ 
Gorbunova NN, Lipskaya NY (1975) Feeding of larvae of the blue marlin Makaira nigricans (Pisces, Istiophoridae). J Ichthyol 15:109-116

Govoni JJ, Boehlert GW, Watanabe Y (1986a) The physiology of digestion in fish larvae. Environ Biol Fishes 16:59-77

Govoni JJ, Ortner PB, Al-yamani F, Hill LC (1986b) Selective feeding of spot, Leiostomus xanthurus, and Atlantic croaker, Micropogonias undulatus, larvae in the northern Gulf of Mexico. Mar Ecol Prog Ser 28:175-183

Govoni JJ, Laban EH, Hare JA (2003) The early life history of swordfish (Xiphias gladius) in the western North Atlantic. Fish Bull 101(4):778-789

Guigand CM, Cowen RK, Llopiz JK, Richardson DE (2005) A coupled asymmetrical multiple opening closing net with environmental sampling system. Mar Technol Soc J 39: $22-24$

Hillgruber N, Kloppmann M (2001) Small-scale patterns in distribution and feeding of Atlantic mackerel (Scomber scombrus L.) larvae in the Celtic Sea with special regard to intra-cohort cannibalism. Helgol Mar Res 55:135-149

Hillgruber N, Haldorson LJ, Paul AJ (1995) Feeding selectivity of larval walleye pollock Theragra chalcogramma in the oceanic domain of the Bering Sea. Mar Ecol Prog Ser 120:1-10

Houde ED (1987) Fish early life dynamics and recruitment variability. Am Fish Soc Symp 2:17-29

Houde ED, Schekter RC (1981) Growth rates, rations and cohort consumption of marine fish larvae in relation to prey concentrations. Rapp P-V Réun Cons Int Explor Mer 178:441-453

Jobling M (1981) Mathematical models of gastric emptying and the estimation of daily rates of food consumption for fish. J Fish Biol 19:245-257

Johannes RE (1978) Reproductive strategies of coastal marine fishes in the tropics. Environ Biol Fishes 3:65-84

Landry MR (2002) Integrating classical and microbial food web concepts: evolving views from the open-ocean tropical Pacific. Hydrobiologia 480:29-39

Lechowicz MJ (1982) The sampling characteristics of electivity indices. Oecologia 52:22-32

Luthy SA, Cowen RK, Serafy JE, McDowell JR (2005) Toward identification of larval sailfish (Istiophorus platypterus), white marlin (Tetrapturus albidus), and blue marlin (Makaira nigricans) in the western North Atlantic Ocean. Fish Bull 103(4):588-600

Manly BFJ, McDonald LL, Thomas DL, McDonald TL, Erickson WP (2002) Resource selection by animals: statistical design and analysis for field studies, 2nd edn. Kluwer Academic Publishers, Dordrecht

> Mullin MM, Onbe T (1992) Diel reproduction and vertical distributions of the marine cladocerans Evadne tergestina and Penilia avirostris in contrasting coastal environments. J Plankton Res 14:41-59

- Novales Flamarique IN, Browman HI (2001) Foraging and prey-search behaviour of small juvenile rainbow trout (Oncorhynchus mykiss) under polarized light. J Exp Biol 204:2415-2422

Paffenhofer GA, Mazzocchi MG (2003) Vertical distribution of subtropical epiplanktonic copepods. J Plankton Res 25: 1139-1156

Pennington M (1985) Estimating the average food consumption by fish in the field from stomach contents data. Dana 5:81-86
Pepin P, Penney RW (1997) Patterns of prey size and taxonomic composition in larval fish: are there general sizedependent models? J Fish Biol 51:84-100

Persson L (1986) Patterns of food evacuation in fishes: a critical review. Environ Biol Fishes 16:51-58

Post JT, Serafy JE, Ault JS, Capo TR, deSylva DP (1997) Field and laboratory observations on larval Atlantic sailfish (Istiophorus platypterus) and swordfish (Xiphias gladius). Bull Mar Sci 60:1026-1034

Postel L, Fock H, Hagen W (2000) Biomass and abundance. In: Harris RP, Wiebe PH, Lenz J, Skjoldal HR, Huntley M (eds) ICES zooplankton methodology manual. Academic Press, San Diego, CA, p 83-192

Richardson DE, Vanwye JD, Exum AM, Cowen RK, Crawford DL (2007) High-throughput species identification: from DNA isolation to bioinformatics. Mol Ecol Notes 7: 199-207

Robertson DR (1991) The role of adult biology in the timing of spawning of tropical reef fishes. In: Sale PF (ed) The ecology of fishes on coral reefs. Academic Press, San Diego, CA, p 356-386

Schekter RC (1971) Food habits of some larval and juvenile fishes from the Florida Current near Miami, Florida. MSc thesis, University of Miami, FL

Shoji J, Tanaka M (2006) Growth-selective survival in piscivorous larvae of Japanese Spanish mackerel Scomberomorus niphonius: early selection and significance of ichthyoplankton prey supply. Mar Ecol Prog Ser 321: $245-254$

Shoji J, Maehara T, Aoyama M, Fujimoto H, Iwamoto A, Tanaka M (2001) Daily ration of Japanese Spanish mackerel Scomberomorus niphonius larvae. Fish Sci 67: $238-245$

Sponaugle S, Denit KL, Luthy SA, Serafy JE, Cowen RK (2005) Growth variation in larval Makaira nigricans. J Fish Biol 66:822-835

Stephens DW, Krebs JR (1986) Foraging theory. Princeton University Press, Princeton

Thorpe JE (1977) Daily ration of adult perch Perca fluviatilis L. during summer in Loch Leven, Scotland. J Fish Biol 11: 55-68

Turner JT (2004) The importance of small planktonic copepods and their roles in pelagic marine food webs. Zool Stud 43:255-266

Uotani I, Ueyanagi S (1997) Feeding habits of Indo-Pacific blue marlin and shortbill spearfish larvae. J Sch Mar Sci Technol Tokai University 43:107-116

Voss GL (1953) A contribution to the life history and biology of the sailfish, Istiophorus americanus Cuv. and Val., in Florida waters. Bull Mar Sci Gulf Caribb 3:206-240

Webber MK, Roff JC (1995) Annual structure of the copepod community and its associated pelagic environment off Discovery Bay, Jamaica. Mar Biol 123:467-479

Whelan CJ, Brown JS (2005) Optimal foraging and gut constraints: reconciling two schools of thought. Oikos 110: 481-496

Wuenschel MJ, Werner RG (2004) Consumption and gut evacuation rate of laboratory-reared spotted seatrout (Sciaenidae) larvae and juveniles. J Fish Biol 65:723-743

Young JW, Davis TLO (1990) Feeding ecology of larvae of southern bluefin, albacore and skipjack tunas (Pisces: Scombridae) in the eastern Indian Ocean. Mar Ecol Prog Ser 61:17-29

Submitted: May 4, 2007; Accepted: November 4, 2007

Proofs received from author(s): March 21, 2008
Editorial responsibility: Howard Browman,

Storebø, Norway 